\title{
Author correction: Relations with parents and identity statuses in the relational domain in emerging adults
}

\author{
Justyna Michałek \\ University of Warmia and Mazury in Olsztyn, Poland
}

\begin{abstract}
After the publication of this article, the author became aware of the fact that there was an error in the cluster analysis that alters part of the results and conclusions of the original work. This erratum contains the corrected version of the part of the paper published in Current Issues in Personality Psychology, 2016, 4(3), 146-154, doi: 10.5114/cipp.2016.61757. The author would like to apologize for any confusion or inconvenience this may have caused.
\end{abstract}

\section{PARTICIPANTS AND PROCEDURE}

\section{MEASURES}

Identity statuses. Personal identity in the relational domain was assessed with the Utrecht-Management of Identity Commitments Scale (U-MICS) (Crocetti et al., 2008; Polish adaptation - Cieciuch, 2010, see: Karaś, Kłym, \& Cieciuch, 2013). According to the measure instructions only participants who are involved in a relationship should fill in the scale. The subscale consists of 13 items rated on a 5-point Likert scale ranging from 1 (completely untrue) to 5 (completely true) and measures the following identity processes: 1) Commitment (5 items; e.g., "My partner gives me security in life"), 2) In-depth exploration (5 items; e.g., "I often reflect on my partner"), 3) Reconsideration of commitment (3 items; e.g., "I often think it would be better to try to find a different partner"). Individuals are classified into specific identity statuses from the combination of these identity processes (cf. Results section). Cronbach's $\alpha$ in the current study ranged from .70 to .91. In the current study the identity processes' intercorrelations suggest that these processes are distinct but interrelated (Crocetti et al., 2008): commitment was weakly and positively associated with in-depth exploration $(r=.36, p<.001)$, in-depth exploration was weakly and negatively correlated with reconsideration of commitment $(r=-.24, p<0.01)$, and commitment was moderately and negatively related to reconsideration of commitment $(r=-.53, p<.001)$.

Relations with parents. The perception of current family relations with parents was measured with the Family Relations Questionnaire (KRR), My Mother and My Father Subscales (Plopa \& Połomski, 2010). Each subscale includes 24 items rated on a 5-point Likert (where 1 represents strong disagreement with regard to the content of statements, while 5 represents total acceptance). My Mother and My Father subscales measure the following dimensions: 1) Communication - the level of openness of the relationship with parents (8 items; e.g., "My mother/my father always finds time to listen to me"), 2) Cohesion - the level and the quality of emotional ties with parents (8 items; e.g., "Even when we argue, I know that my mother/my father still loves me"), 3) Autonomy-control - the level of given autonomy (the higher the score, the higher 
the level of given autonomy, vs. the lower the level, the higher the control) (8 items with reverse scoring; e.g., "My mother/my father meddles too much in my life"). Cronbach's $\alpha$ ranged from .85 to .90 .

\section{RESULTS}

\section{CREATING IDENTITY STATUSES}

To analyse personal identity using a person-centered approach (Crocetti et al., 2012), cluster analyses using $\mathrm{k}$-means and simple Euclidean distance were used on standardized scores of identity processes in the relational domain: commitment, in-depth exploration, and reconsideration of commitment ${ }^{1}$. The final decision on the interpretation of the cluster solutions was guided by theoretical conceptualizations of identity statuses and the level of explanation of the variance in each of the identity dimensions (the cluster solution had to explain approximately $50 \%$ of the variance in each of the identity processes) ${ }^{2}$.

Figure 1 presents the means of the identity dimensions in the relational domain of the 4 groups in the final cluster solution ${ }^{3}$. The first cluster, which represents achievement status, included 72 participants (27\%, 46 females, 26 males) scoring high on commitment and in-depth exploration, but low on reconsideration of commitment. The second cluster consisted of 32 individuals (12\%, 15 females, 17 males) scoring high scores on commitment, and low scores on indepth exploration and reconsideration of commitment (early closure status). The third cluster included 26 emerging adults $(10 \%, 13$ females, 13 males) who scored low on commitment and in-depth exploration, but high on reconsideration of commitment (moratorium status). The fourth cluster comprised 53 participants (39\%, 23 females, 30 males) scoring low on commitment, in-depth exploration as well as reconsideration of commitment (diffusion status). Seventy-nine emerging adults (30\%, 45 females, 34 males) were not in an intimate relationship and did not fill in the identity measure. Thus, the expectations of finding four identity statuses (without diffusion status) in a Polish sample of emerging adults were not confirmed.

\section{AGE AND GENDER DIFFERENCES IN IDENTITY STATUSES}

The $\chi^{2}$ test was conducted to examine the gender differences in the identity statuses' distribution. Consistent with the expectations, no significant gender differences were found, $\chi^{2}=5.956(3, N=183), p=.11$. In addition, a one-way ANOVA indicated that there were no associations between age and four identity statuses, $F(3,179)=.86, p=.46$.

\section{Figure 1}

Z-scores for commitment, in-depth exploration, and reconsideration of commitment for the four identity statuses in the relational domain

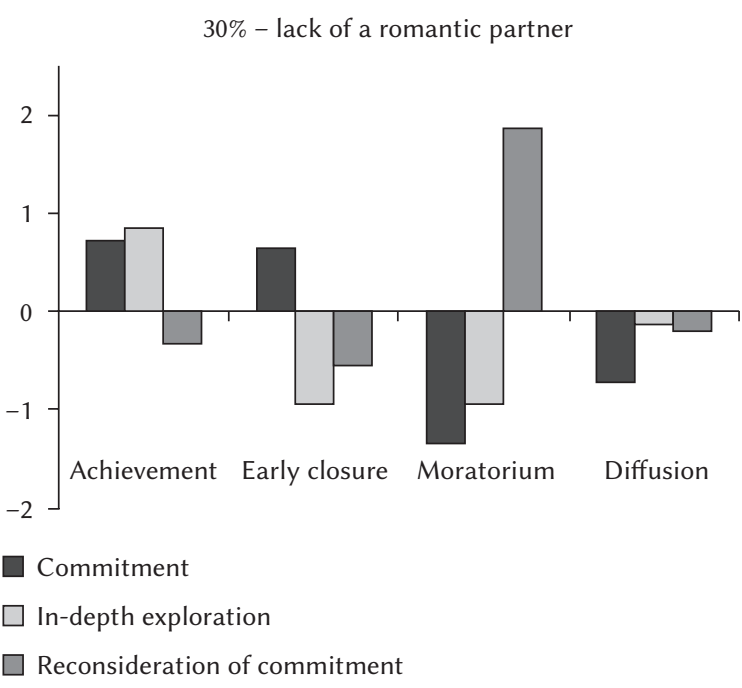

\section{IDENTITY STATUS DIFFERENCES IN PERCEPTION OF RELATIONS WITH PARENTS}

To examine differences in relations with mother and father reported by participants classified into the various identity statuses in the relational domain an analysis of variance (ANOVA) was performed. The results indicated that identity statuses had effects on perception of autonomy given by parents $(p<.05)$ (see Table 2). Tukey post hoc comparisons showed that individuals in the moratorium status reported less autonomy given by the mother than individuals in the status of achievement, early closure and participants without a partner. Concerning autonomy given by the father, individuals in the moratorium status reported higher control than individuals in the status of achievement and participants without a romantic partner. Thus, these results confirmed the role of the perception of given autonomy by parents; less given autonomy was perceived by individuals in moratorium than in other statuses or without a romantic partner. The hypothesis about the cohesion and identity statuses was not confirmed.

\section{DISCUSSION}

\section{IDENTITY STATUSES IN RELATIONAL DOMAIN AMONG EMERGING ADULTS}

In order to gain a better understanding of this issue, a person-centered approach has been used (Crocetti et al., 2012). The four identity statuses were extracted 
Table 2

Means of relations with mother and father by identity statuse

\begin{tabular}{|c|c|c|c|c|c|c|c|}
\hline \multirow[t]{2}{*}{ Variable } & \multicolumn{5}{|c|}{ Identity statuses } & \multirow[t]{2}{*}{$F(\mathrm{df})$} & \multirow[t]{2}{*}{$\eta^{2}$} \\
\hline & A & $\mathrm{E}$ & M & D & $\mathrm{L}$ & & \\
\hline \multicolumn{8}{|l|}{ Mother } \\
\hline Communication & $\begin{array}{l}31.23 \\
(6.19)\end{array}$ & $\begin{array}{l}31.47 \\
(5.94)\end{array}$ & $\begin{array}{l}29.50 \\
(5.43)\end{array}$ & $\begin{array}{l}28.96 \\
(5.42)\end{array}$ & $\begin{array}{l}30.60 \\
(6.22)\end{array}$ & $\begin{array}{c}1.51 \\
(4,249)\end{array}$ & .02 \\
\hline Cohesion & $\begin{array}{l}32.76 \\
(5.55)\end{array}$ & $\begin{array}{l}32.50 \\
(5.51)\end{array}$ & $\begin{array}{l}30.31 \\
(5.55)\end{array}$ & $\begin{array}{l}30.70 \\
(5.27)\end{array}$ & $\begin{array}{l}31.18 \\
(6.28)\end{array}$ & $\begin{array}{c}1.62 \\
(4,249)\end{array}$ & .03 \\
\hline Autonomy & $\begin{array}{l}32.94^{\mathrm{a}} \\
(5.77)\end{array}$ & $\begin{array}{c}33.91^{\mathrm{ac}} \\
(6.01)\end{array}$ & $\begin{array}{l}28.86^{\mathrm{b}} \\
(6.56)\end{array}$ & $\begin{array}{l}31.68 \\
(4.92)\end{array}$ & $\begin{array}{c}32.81^{\mathrm{acd}} \\
(5.65)\end{array}$ & $\begin{array}{c}3.12^{*} \\
(4,249) \\
\end{array}$ & .05 \\
\hline \multicolumn{8}{|l|}{ Father } \\
\hline Communication & $\begin{array}{l}28.12 \\
(7.98)\end{array}$ & $\begin{array}{l}26.43 \\
(7.93)\end{array}$ & $\begin{array}{l}28.05 \\
(6.95)\end{array}$ & $\begin{array}{l}27.17 \\
(7.03)\end{array}$ & $\begin{array}{l}27.87 \\
(6.90)\end{array}$ & $\begin{array}{c}.36 \\
(4,236)\end{array}$ & .01 \\
\hline Cohesion & $\begin{array}{l}29.03 \\
(7.98)\end{array}$ & $\begin{array}{l}27.27 \\
(7.55)\end{array}$ & $\begin{array}{l}27.48 \\
(7.08)\end{array}$ & $\begin{array}{l}27.52 \\
(7.57)\end{array}$ & $\begin{array}{l}28.09 \\
(7.08)\end{array}$ & $\begin{array}{c}.46 \\
(4,236)\end{array}$ & .01 \\
\hline Autonomy & $\begin{array}{l}32.19^{\mathrm{a}} \\
(6.07)\end{array}$ & $\begin{array}{l}32.20 \\
(5.83)\end{array}$ & $\begin{array}{l}28.00^{\mathrm{b}} \\
(7.73)\end{array}$ & $\begin{array}{l}31.96 \\
(5.49)\end{array}$ & $\begin{array}{c}33.17^{\mathrm{ac}} \\
(6.02)\end{array}$ & $\begin{array}{c}2.99^{*} \\
(4,236)\end{array}$ & .05 \\
\hline
\end{tabular}

Note. A - Achievement, E - Early closure, M - Moratorium, D - Diffusion, L - lack of a romantic partner. An identity status mean is significantly different from another mean if they have different superscripts. A mean without a superscript is not significantly different from any other mean, ${ }^{*} p<.05$.

in a sample of Polish emerging adults. Thus, the identities of achievement, early closure, moratorium and diffusion differentiate Polish emerging adults (Crocetti et al., 2012). Evidence of a diffused status characterized by a low score on all the identity processes was found, which is contrary to expectations but is consistent with Marcia's original model of identity statuses (1980).

\section{IDENTITY STATUSES IN RELATIONAL DOMAIN AND RELATIONS WITH PARENTS AMONG EMERGING ADULTS}

Furthermore, the profile of youth in different identity statuses in the relation domain in terms of perceived relations with mother and father was examined. Using a person-centered approach (Crocetti et al., 2012), it was found that individuals' classifications in various identity statuses in the relational domain and individuals not involved in a romantic relationship were significantly associated only with the perception of given autonomy (both mother and father). Individuals in the moratorium status perceived their mothers as having given less autonomy than individuals in the status of achievement, early closure and participants without a romantic partner. In addition, individuals in the moratorium status also perceived their fathers as having given less autonomy than individuals in the status of achievement and participants without a romantic partner. Unexpectedly, perceived parents-emerging adult cohesion was not associated with identity statuses. These results suggest that growth in personal independence from parents might play an important role in successful transition from singleness to stable partnerships, especially for individuals who experience a crisis in this domain of identity development, which is consistent with the previous studies (Kins \& Beyers, 2010; Koepke \& Denissen, 2012).

\section{IMPLICATIONS}

The current study has theoretical and practical implications. From a theoretical point of view, the results suggest the importance of examining identity in the relational domain, not only in the family context. Thus, it is important to propose a more straightforward model of identity formation in this domain.

Since more than half of the participating emerging adults were in the moratorium status, diffusion status or were not involved in a romantic relationship (10\%, 39\%, 30\%, respectively), early screening of those groups and psychosocial interventions aimed at supporting their identity formation taking into account relations with parents could be important for clinicians and practitioners. 


\section{CONCLUSIONS}

The current study provided an original contribution to the literature by focusing on the family role for the occurrence of identity statuses among emerging adults and considering the relational identity domain which is relevant for transition to adulthood. The main results highlighted that transition toward adulthood, especially from singleness to stable partnerships, seemed to be challenging. Moreover, relations with mother and father are linked to identity statuses in the relational domain. In particular, the perception of low autonomy given by parents was related to less mature identity status (moratorium) in this domain. Thus, the findings suggest that the family play an important role in the development of a mature identity in the relational domain and that emerging adults should be supported in finding fulfilling commitments in close relationships, in the family context. It is important to continue this work and attain more in-depth understanding of identity formation in the relational domain, especially nowadays in the context of observed progressively postponing transition to adulthood.

\section{ENDNOTES}

1 Because outliers can affect the results of a cluster analysis, first, 4 outliers were removed (participants who scored 3 SDs away from the sample mean on one or more of the identity variables).

2 The ANOVA confirmed that the clusters have been chosen to maximize the differences among cases in different clusters: commitment, $F(3,179)=134.12, p<.001$; in-depth exploration, $F(3,179)=79.94, p<.001$; reconsideration of commitment, $F(3,179)=111.81, p<.001$.

3 The two-step clustering procedure (Crocetti et al., 2008; Gore, 2000) gave almost the same results as obtained by the k-means clustering method ( $89.4 \%$ correspondence for the four-cluster solution).

\section{References}

Gore, P. A. (2000). Cluster analysis. In: H. E. A. Tinsley \& S. D. Brown (Eds.). Handbook of Applied Multivariate Statistics and Mathematical Modelling (pp. 297-321). Academic Press. 